University of Wollongong

Research Online

Faculty of Engineering - Papers (Archive)

Faculty of Engineering and Information

Sciences

February 1994

\title{
Performance of embankment stabilized with vertical drains on soft clay
}

Buddhima Indraratna

University of Wollongong, indra@uow.edu.au

A. S. Balasubramaniam

Asian Institute of Technology, Bangkok, Thailand

P. Ratnayake

University of Peradeniya, Sri Lanka

Follow this and additional works at: https://ro.uow.edu.au/engpapers

Part of the Engineering Commons

https://ro.uow.edu.au/engpapers/213

\section{Recommended Citation}

Indraratna, Buddhima; Balasubramaniam, A. S.; and Ratnayake, P.: Performance of embankment stabilized with vertical drains on soft clay 1994.

https://ro.uow.edu.au/engpapers/213

Research Online is the open access institutional repository for the University of Wollongong. For further information contact the UOW Library: research-pubs@uow.edu.au 


\title{
Performance of Embankment Stabilized with Vertical Drains on Soft Clay
}

\author{
By B. Indraratna, ${ }^{1}$ Member, ASCE, A. S. Balasubramaniam, ${ }^{2}$ \\ Fellow, ASCE, and P. Ratnayake ${ }^{3}$
}

\begin{abstract}
This study describes the performance of a full-scale embankment raised on a soft marine clay, stabilized with vertical band drains in Malaysia. The finite element code CRISP, which is based on critical-state soil mechanics, has been employed to investigate the performance of the embankment and the underlying soft clay. Predictions of the excess pore pressures and both vertical and lateral displacements are made and compared with field observations. The limited use of closed-form solutions for the prediction of settlements at the line of symmetry of the embankment is also discussed. The effectiveness of the prefabricated drains has been evaluated according to the rate of excess-pore-pressure dissipation at the soil-drain interface. The numerical approach is based on a coupled consolidation analysis rather than on a conventional, purely undrained analysis. The numerical analysis reveals that for efficient vertical drains, the influence of smear and well resistance can be ignored. While the assumption of perfect drains may be acceptable in the long term, the short-term settlements are governed by the drain efficiency.
\end{abstract}

\section{INTRODUCTION}

This study is concerned with the behavior of a full scale embankment with vertical band drains, constructed by the Malaysian Highway Authority (Proceedings 1989) on the Muar coastal plain, slightly north of the Malaysian North-South Expressway (Fig. 1). In fact, a comprehensive array of 14 such embankments was built in the same site with nine different ground-improvement techniques to assess the relative merits of various soil-stabilization schemes. One embankment was constructed to failure without any soil-improvement techniques for the purpose of comparison. Its behavior was analyzed and discussed in detail in a previous paper (Indraratna et al. 1992).

The current study provides a means of evaluating the effectiveness of vertical band drains in improving soft soil foundations subjected to embankment loading. The maximum completed height of the embankment was $4.75 \mathrm{~m}$, and it was constructed over a period of four months. The embankment fill consisted of a granitic residual soil compacted to a unit weight of $25 \mathrm{kN} / \mathrm{m}^{3}$. Underneath the embankment, fully penetrating vertical band drains were installed in a triangular pattern. The prefabricated drains consisted of polyolefine cores (rectangular cross section) with 24 channels. The sides of the drains were perforated with $0.2-\mathrm{mm}$-diameter holes at $2-\mathrm{mm}$ centers. A cross section through the center of the embankment is shown in Fig. 2. The drain parameters relevant for the analysis are summarized as follows.

${ }^{1}$ Lect., Dept. of Civ. and Mining Engrg., Univ. of Wollongong, P.O. Box 1144, Northfields Avenue, Wollongong, New South Wales 2500, Australia.

${ }^{2}$ Prof., Div. of Geotech. Engrg., Asian Inst. of Tech., G.P.O. Box 2754, Bangkok, Thailand.

${ }^{3}$ Lect., Dept. of Civ. Engrg., Univ. of Peradeniya, Sri Lanka.

Note. Discussion open until July 1, 1994. To extend the closing date one month, a written request must be filed with the ASCE Manager of Journals. The manuscript for this paper was submitted for review and possible publication on May 15, 1992. This paper is part of the Journal of Geotechnical Engineering, Vol. 120, No. 2, February, 1994. (ASCE, ISSN 0733-9410/94/0002-0257/\$1.00 + \$.15 per page. Paper No. 4065 . 


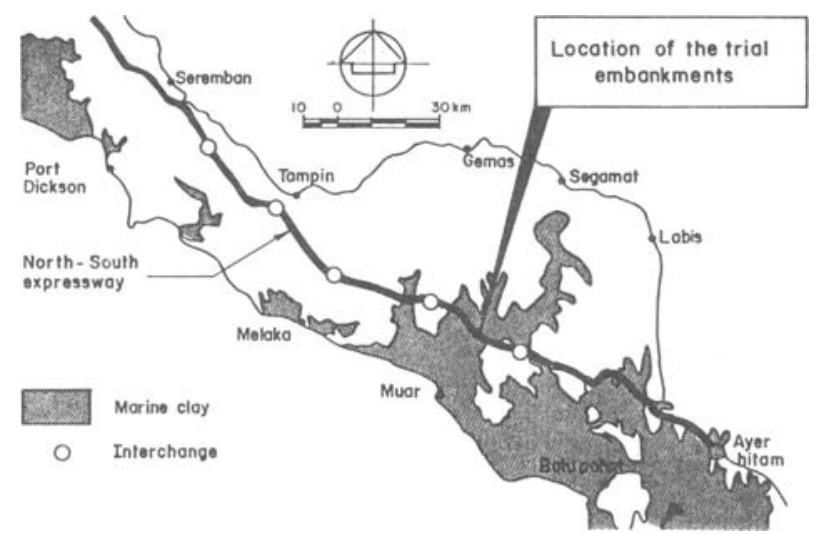

FIG. 1. Location of Marine Clay Deposits and Trial Embankments

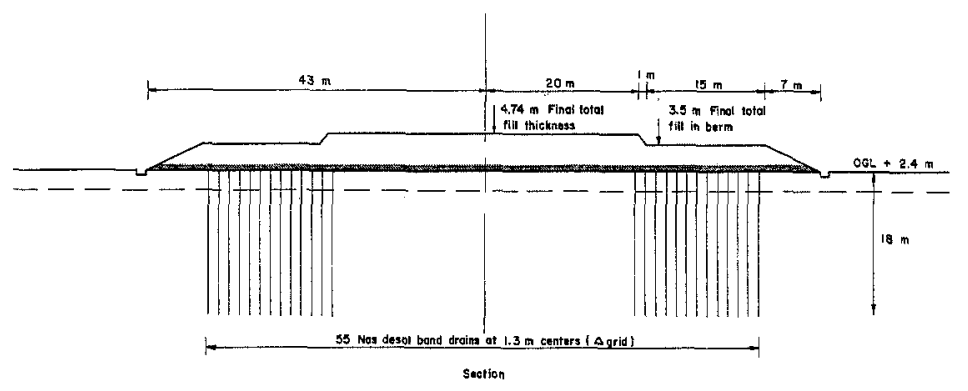

FIG. 2. Cross Section through Centerline of Embankment with Vertical Drains

- Drain pattern: triangular

- Maximum length: $18.0 \mathrm{~m}$

- Drain spacing: $1.30 \mathrm{~m}$

- Cross section: $95 \mathrm{~mm} \times 2 \mathrm{~mm}^{2}$

- Equivalent diameter: $70 \mathrm{~mm}$

- Influence-zone diameter: $1.365 \mathrm{~m}$

- Smeared-zone diameter: $400 \mathrm{~mm}$

The paper describes the predicted and measured behavior of the embankment and the underlying soft clay foundation. The effectiveness of the band drains is evaluated on the basis of excess-pore-pressure dissipation and both vertical and lateral displacements. The foundation response is modeled according to the modified cam-clay theory, incorporated in the finite element method. The relevant soil parameters were determined by undrained, $K_{0}$-consolidation triaxial tests. In the finite element code (CRISP), the field behavior was simulated using a coupled (Biot) consolidation model, rather than a purely undrained analysis, which proved to be more realistic for this particular soil (Indraratna et al. 1992). The compression of the soft clay with vertical drains was also determined by the analytical solution proposed by Barron (1948), which combines the radial and vertical consolidation phases. The predictions made from these different methods were 
compared with the observed field measurements. It is shown that the discrepancy between the observations and predictions is acceptable, and that the vertical drains are effective in accelerating the stabilization of the soft clay.

\section{SOIL CONDITIONS IN TEST SITE}

A detailed soil profile including the grain size distribution and mineralogy was given by Indraratna et al. (1992). Therefore, only a summary is presented here. The clays along the west coast of peninsular Malaysia constitute a coastal plain of marine clay up to $20 \mathrm{~m}$ thick, with an average lateral extent of about $25 \mathrm{~km}$. The subsurface geology data at the site reveal the existence of a weathered crust of about $2.0 \mathrm{~m}$ above a $16.5-\mathrm{m}$-thick layer of soft silty clay. The soft silty clay can be further divided into an upper very soft layer and a lower soft silty clay. Immediately beneath this lower clay layer is a $0.3-0.5-\mathrm{m}$-thick peaty soil followed by a stiff sandy clay. The clay ends at a dense sand layer beyond $22.5 \mathrm{~m}$ below ground level, although a distinct interface cannot be identified. The variations of the water content, liquid and plastic limits, and consolidation parameters with depth are presented in Fig. 3. Although many soft clays in Southeast Asian countries are generally normally consolidated, light overconsolidation caused by surface desiccation and weathering is sometimes exhibited toward the surface, as shown by this marine clay. It was also determined that the unit weight of the clay with depth was fairly consistent between $15-16 \mathrm{kN} / \mathrm{m}^{3}$, except at the topmost crust, where the unit weight approached $17 \mathrm{kN} / \mathrm{m}^{3}$. The field permeability varied from $1-2 \times 10^{-9} \mathrm{~m} / \mathrm{s}$ with increasing depth within the soft clay layer.

The undrained shear strength, as measured by the field vane, had a

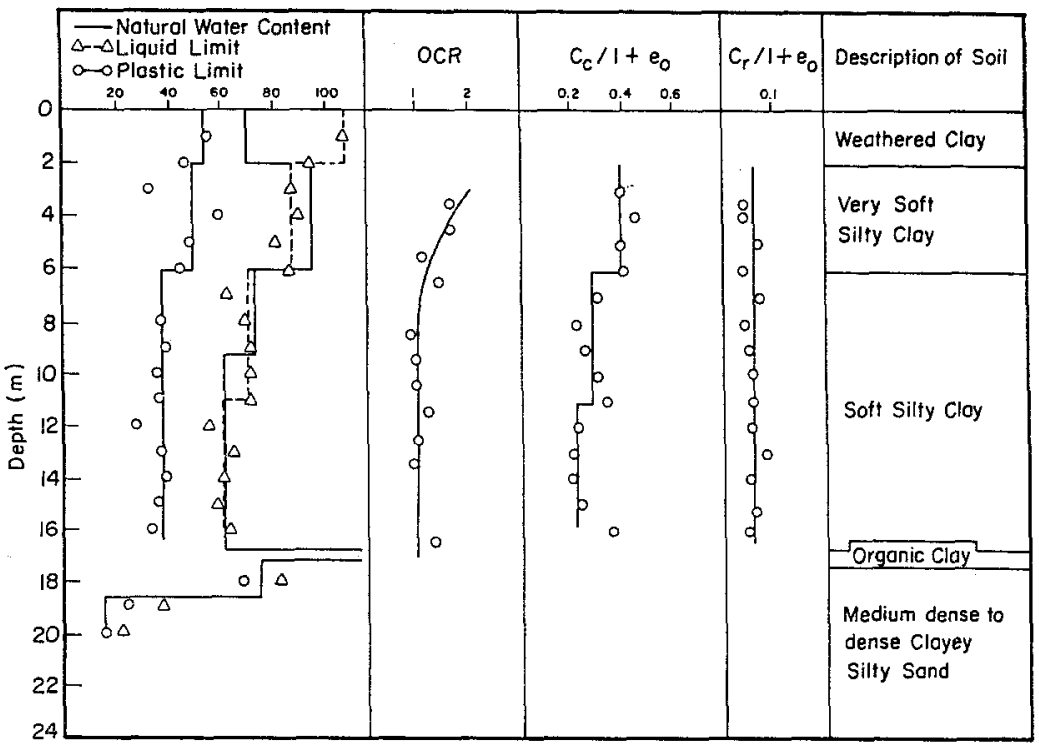

FIG. 3. Geotechnical Properties of Muar Clay (Data Provided by Malaysian Highway Authority, Kuala Lumpur, Malaysia) 
TABLE 1. Variation of Strength and Consolidation Parameters

\begin{tabular}{|c|c|c|c|c|c|}
\hline $\begin{array}{l}\text { Depth } \\
(\mathrm{m}) \\
(1)\end{array}$ & $\begin{array}{c}E_{u} \\
(\mathrm{kPa}) \\
(2) \\
\end{array}$ & $\begin{array}{c}c^{\prime} \\
(\mathrm{kPa}) \\
(3)\end{array}$ & $\begin{array}{c}\phi^{\prime} \\
\text { (degrees) } \\
(4)\end{array}$ & $\begin{array}{c}c_{\nu} \times 10^{-4} \\
\left(\mathrm{~cm}^{2} / \mathrm{s}\right) \\
(5)\end{array}$ & $\begin{array}{c}c_{h} \times 10^{-4} \\
\left(\mathrm{~cm}^{2} / \mathrm{s}\right) \\
(6)\end{array}$ \\
\hline $0-2$ & 25,500 & 8 & 12.5 & 7.5 & 10.0 \\
\hline $2-5$ & 6,600 & 14 & 14 & 30.0 & 40.0 \\
\hline $5-8$ & 8,933 & 22 & 7 & 15.0 & 23.5 \\
\hline $8-11$ & 9,120 & 9 & 20 & 13.0 & 15.0 \\
\hline $11-14$ & 6,593 & 16 & 17 & 16.0 & 22.0 \\
\hline $14-18$ & 5,884 & 14 & 21.5 & 5.5 & 8.5 \\
\hline
\end{tabular}

TABLE 2. Modified Cam-Clay Parameters Required for Numerical Analysis (CRISP)

\begin{tabular}{c|c|c|c|c|c|c|c|c|c}
\hline \hline $\begin{array}{c}\text { Depth } \\
(\mathrm{m})\end{array}$ & $\begin{array}{c}\mathrm{K} \\
(2)\end{array}$ & $\begin{array}{c}\lambda \\
(3)\end{array}$ & $\begin{array}{c}e_{c s} \\
(4)\end{array}$ & $\begin{array}{c}M \\
(5)\end{array}$ & $\begin{array}{c}v \\
(6)\end{array}$ & $\begin{array}{c}K_{w} \\
\left(\times 10^{4}\right) \\
(7)\end{array}$ & $\begin{array}{c}\gamma_{s} \\
\left(\mathrm{kN/m} / \mathrm{m}^{3}\right) \\
(8)\end{array}$ & $\begin{array}{c}k_{h} \\
(\mathrm{~m} / \mathrm{s}) \\
(9)\end{array}$ & $\begin{array}{c}k_{v} \\
(\mathrm{~m} / \mathrm{s}) \\
(10)\end{array}$ \\
\hline $0-1.75$ & 0.06 & 0.16 & 3.10 & 1.19 & 0.29 & 4.4 & 16.5 & $6.4 \times 10^{-9}$ & $3.0 \times 10^{-9}$ \\
$1.75-5.50$ & 0.06 & 0.16 & 3.10 & 1.19 & 0.31 & 1.1 & 15.0 & $5.2 \times 10^{-9}$ & $2.7 \times 10^{-9}$ \\
$5.50-8.0$ & 0.05 & 0.13 & 3.06 & 1.12 & 0.29 & 2.4 & 15.5 & $3.1 \times 10^{-9}$ & $1.4 \times 10^{-9}$ \\
$8.0-18.0$ & 0.035 & 0.09 & 1.61 & 1.07 & 0.26 & 22.7 & 16.0 & $1.3 \times 10^{-9}$ & $0.6 \times 10^{-9}$ \\
\hline
\end{tabular}

minimum value of about $8 \mathrm{kPa}$ at a depth of $3 \mathrm{~m}$, and this increased approximately linearly with depth. The corrected field-vane strengths as proposed by Bjerrun (1973) have been used in the numerical analysis. Only limited information was available with regard to the thin peaty soil layer (less than $0.5 \mathrm{~m}$ thick) at a depth of about $18 \mathrm{~m}$ below the ground level. Consequently, for the purpose of analysis, the effect of this peat layer has been ignored. In addition to the in situ data, a considerable amount of laboratory information was acquired for the subsurface clay deposits prior to the construction of the test embankment. These included oedometer consolidation tests and unconsolidated undrained (UU), consolidated isotropically undrained (CIU), and consolidated drained (CD) triaxial tests. The undrained modulus $\left(E_{u}\right)$, effective strength parameters $\left(c^{\prime}\right.$ and $\left.\phi^{\prime}\right)$, and the vertical and horizontal coefficient of consolidation $\left(c_{v}\right.$ and $\left.c_{h}\right)$ are summarized in Table 1 . Consolidation tests were done on both vertically and horizontally oriented specimens (Ratnayake 1991). Furthermore, a series of specialized triaxial tests were also conducted, including constant stress ratio tests, effective and total stress path tests, and anisotropically consolidated undrained (CU) tests. The results of these tests provided the appropriate modified cam-clay model parameters of the subsoils (Table 2), for the prediction of displacements and pore-pressure changes beneath the test embankment. The cam-clay parameters (Roscoe and Burland 1968) include the gradients of volume against log pressure relations for consolidation and swelling ( $\lambda$ and $\kappa$, respectively); slope of the critical state line based on effective stresses $(M)$; void ratio at unit consolidation pressure $\left(e_{c s}\right)$; bulk modulus $(K)$; horizontal and vertical permeabilities $\left(k_{h}\right.$ and $\left.k_{v}\right)$; and Poisson's ratio $(v)$.

\section{NUMERICAL ANALYSIS}

The critical-state finite element program CRISP was developed at Cambridge University, Cambridge, England. It incorporates the modified camclay constitutive model and enables coupled (Biot) consolidation analysis 
to be carried out, in addition to the purely undrained or drained analysis. The coupled behavior includes both undrained deformations and the drained settlements. It has been shown earlier that the modified cam-clay model is accurate in representing the undrained deformation behavior of soft Muar clay (Balachandran 1990). In the past, CRISP has proved to be accurate and consistent for predicting the deformation response of normally consolidated to lightly overconsolidated soils (Britto and Gunn 1987).

The horizontal permeability of the soft Muar clay foundation exceeds the vertical permeability. The results predicted using CRISP were subsequently compared with the actual field observations. The performance of the vertical drains was evaluated as discussed in the following.

As a preliminary finite-element-method (FEM) exercise, the settlements based on a single vertical drain under embankment loading were analyzed using the coupled consolidation model for an axisymmetric, perfect drain. Comparison of these results with the analytical solutions enabled the proper calibration of CRISP. The diameter of the individual influence-zone diameter for this triangular pattern of drains is $1.365 \mathrm{~m}$ (Ratnayake 1991). As the in situ horizontal (lateral) permeability for the subsoils is at least double the permeability in the vertical direction, the total compression is a function of both vertical and radial drainage. The extent of the smeared zone was estimated according to Hansbo (1981), and was $0.4 \mathrm{~m}$, or almost twice the equivalent diameter of the mandrel. For the finite element analysis, the horizontal permeability of the smeared zone was reduced to equal the vertical permeability.

To compute lateral and vertical displacements, excess pore-water pressures, and surface settlements corresponding to the sequential construction of the embankment, linear-strain-quadrilateral (LSQ) elements were used in the finite element discretization of the clay foundation (Fig. 4). The eightnode LSQ elements are characterized by additional pore pressure degrees of freedom at the four corner nodes; the pore pressures vary linearly over the element. For the influence zone of the vertical drains, the finite element mesh was made relatively fine (Fig. 4). The axes of drains coincide with every other vertical line of this fine mesh, where the spacing between the drains consists of two rows of LSQ elements. In the case of perfect drains (no clogging and smearing), excess pore pressures at the drain boundaries are considered to be zero. Nevertheless, partial clogging of synthetic drains retards the rate of dissipation of excess pore pressures. In this analysis, the undissipated excess pore pressures were computed using additional porepressure shape functions applied to nodes along the drain boundaries. For the case of perfect drains, the excess pore pressures at these nodes would be always set to zero. The modified pore-pressure subroutines used in conjunction with CRISP are discussed in detail by Ratnayake (1991).

A foundation depth of $18.0 \mathrm{~m}$ was considered to be sufficient, as the soil layers beyond this depth were considerably stiffer than the upper soft clay

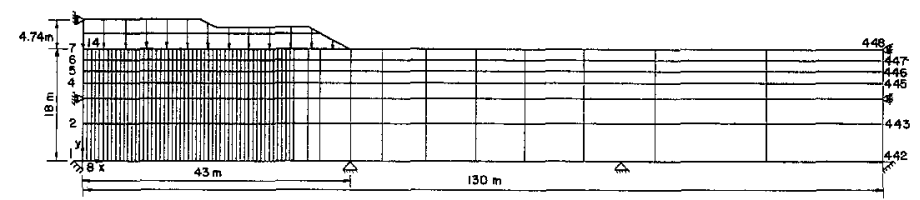

FIG. 4. Finite Element Discretization of Embankment and Subsoils with Vertical Drains 
layer. This assumption was justified independently by Balachandran (1990) and Ratnayake (1991). The lateral boundary of the finite element mesh is defined at a distance of seven times the vertical depth from the centerline or three times the vertical depth from the embankment toe. The clay foundation is divided into six horizontal layers, representing the variation of soil properties within the subsurface deposits. The actual performance of the drains could be evaluated comparing the FEM results with the field measurements. In addition, along the centerline of the embankment, Barron's (1948) consolidation theory with radial flow was also employed. The surface loading imposed by the embankment is assumed to be rigid in Barron's (1948) solution; thus, the equal strain solution is considered to be appropriate. The performance of the embankment on the improved foundation could be evaluated with respect to perfect drains, drains with smeared zones, and well resistance.

The associated soil deformation can be simulated by determining the relevant critical-state parameters correctly. The laboratory procedure for the determination of the fundamental cam-clay parameters by triaxial tests is discussed in detail by Britto and Gunn (1987). The values of modified cam-clay parameters obtained from $C K_{0} U$ triaxial tests and employed in the analysis are summarized in Table 2 . The variations of the unit weight $\left(\gamma_{t}\right)$ as well as horizontal and vertical permeabilities $\left(k_{x}\right.$ and $\left.k_{y}\right)$ with depth as obtained from in situ tests are also tabulated. The cam-clay properties of the thin weathered crust have been assumed to be the same as those obtained for the silty clay layer just beneath it, in the absence of sufficient data for surface samples.

The surcharge loading imposed on the soft foundation by the compacted embankment is based on a unit weight of $20.5 \mathrm{kN} / \mathrm{m}^{3}$. The rate of loading is a function of the construction history of the embankment as summarized in Table 3. The geotechnical properties of the fill are as follows.

- Bulk density: $20.4-20.9 \mathrm{kN} / \mathrm{m}^{3}$

- Dry density: $17.5-18.6 \mathrm{kN} / \mathrm{m}^{3}$

- Liquid limit: $96-117 \%$

- Plastic limit: $38-46 \%$

- Plasticity index: $56-71 \%$

- Consolidated drained (CD) triaxial tests: $c_{d}^{\prime}=14.2 \mathrm{kPa}$, and $\phi_{d}^{\prime}=$ $31.3^{\circ}$

The enhanced shear strength of the compacted residual fill (sandy clay) is evident from the results of consolidated drained triaxial tests, which indicate a friction angle $\left(\phi^{\prime}\right)$ of $31^{\circ}$. The in situ stress conditions required in the numerical analysis are presented in Table 4 , including the effective stresses $\left(\sigma_{x o}^{\prime}\right.$ and $\sigma_{y o}^{\prime}$ ), isotropic preconsolidation pressure $\left(p_{c}\right)$, and the variation of ground-water pressure $(u)$ with depth.

TABLE 3. Construction History of Embankment

\begin{tabular}{c|c|c|c|c}
\hline \hline $\begin{array}{c}\text { Stage } \\
(1)\end{array}$ & $\begin{array}{c}\text { Fill period } \\
\text { (days) } \\
(2)\end{array}$ & $\begin{array}{c}\text { Fill thickness } \\
(\mathrm{m})\end{array}$ & $\begin{array}{c}\text { Rate of filling } \\
(\mathrm{m} / \mathrm{day}) \\
(4)\end{array}$ & $\begin{array}{c}\text { Rest period } \\
\text { (days) } \\
(5)\end{array}$ \\
\hline 1 & $1-14$ & $0.0-2.57$ & 0.18 & $14-105$ \\
2 & $105-129$ & $2.57-4.74$ & 0.09 & $129-$ present \\
\hline
\end{tabular}


TABLE 4. In Situ Stress Conditions at Muar Embankment Site

\begin{tabular}{c|c|c|c|c}
\hline \hline $\begin{array}{c}\text { Depth } \\
(\mathrm{m})\end{array}$ & $\begin{array}{c}\sigma_{h o} \\
(\mathrm{kPa}) \\
(1)\end{array}$ & $\begin{array}{c}\sigma_{v o} \\
(\mathrm{kPa}) \\
(3)\end{array}$ & $\begin{array}{c}u \\
(\mathrm{kPa}) \\
(4)\end{array}$ & $\begin{array}{c}p_{c} \\
(\mathrm{kPa}) \\
(5)\end{array}$ \\
\hline 0 & 0 & 0 & 0 & 110 \\
1.75 & 17.3 & 28.9 & 0.0 & 95 \\
5.5 & 29.1 & 48.4 & 36.7 & 44 \\
8.0 & 37.6 & 62.6 & 61.3 & 60 \\
18.0 & 74.8 & 124.6 & 159.3 & 65 \\
\hline \hline
\end{tabular}

\section{FIELD MEASUREMENTS AND PREDICTIONS}

Certain simplifications have been made in the numerical analysis. For instance, some soil properties of the topmost crust have been assumed to be the same as those of the upper-clay-layer deposit, in the absence of reliable laboratory or field data. Also, the effect of the thin peat layer has been ignored due to its considerable depth below the ground level. The test embankment is compacted with a residual fill prone to tensile cracking at certain differential settlements, regardless of its enhanced shear resistance (Indraratna et al. 1990). The effect of the tensile properties of the embankment fill on the numerical predictions was ignored, as the embankment fill was considered as a surcharge loading applied on the foundation surface in two stages of construction (Fig. 4). Furthermore, the excess pore pressures at the drain-soil interfaces for perfect drains at any given time are considered to be zero. In practice, the pore-pressure dissipation may not be instantaneous, due to partial clogging among other factors. The lateral fixity of the finite element mesh (boundary) and the assumption of plane strain cause inevitable deviations from the actual three-dimensional state.

The soft clay foundation was extensively instrumented to monitor the lateral and vertical movements and the development of excess pore-water pressures. The settlements beneath the embankment were measured with the aid of extensometers and settlement gages, while the lateral displacements were determined from the inclinometer readings (Fig. 5). The pore pressures were measured with pneumatic piezometers, and their locations are shown in Fig. 6. The positions of the vertical band drains (shown earlier in Fig. 2) are not marked in Figs. 5 and 6 for diagramatic clarity.

\section{Pore Pressures beneath Embankment}

The time-dependent pore-pressure variations along the centerline of the embankment $(\mathrm{P} 4-\mathrm{P} 7)$ and $23.3 \mathrm{~m}$ to the left of the centerline $(\mathrm{P} 1-\mathrm{P} 3)$ were monitored by pneumatic piezometers (Fig. 6). These instruments were located within the influence zone, i.e., triangular grid pattern (1.3-m spacing) of the vertical drains. In the two-dimensional plane strain analysis, the finite element predictions are computed at the corresponding depth, but not necessarily at the exact location (in plan) of the piezometers. As a result, the two-dimensional predictions can deviate from accuracy. However, as the piezometers are located within the influence zone of the closely spaced drains, the error can be considered to be small.

Since the soft clay below a depth of $8 \mathrm{~m}$ from the original ground surface is normally consolidated (Fig. 3), the prediction of excess pore pressures by modified cam-clay can be regarded as reliable for these soil layers. For the deposits close to the ground surface, the overconsolidation ratio ap- 


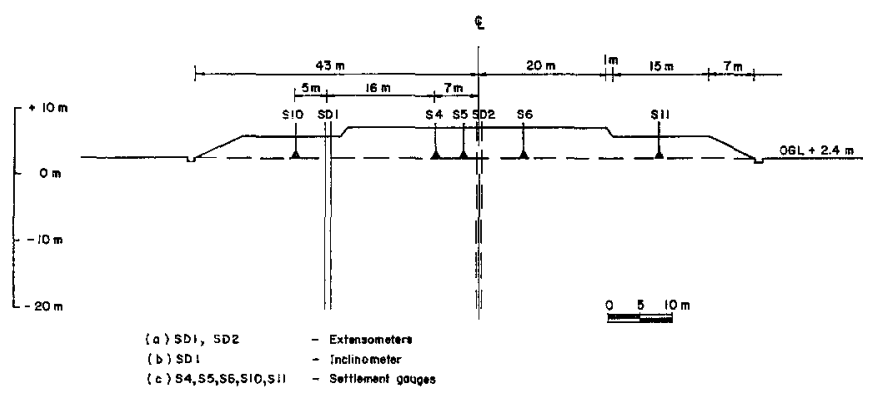

FIG. 5. Location of Settlement Gages and Inclinometers

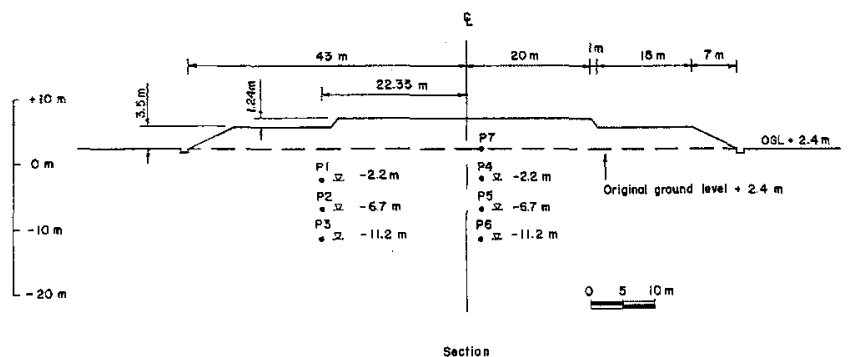

FIG. 6. Location of Pneumatic Piezometers
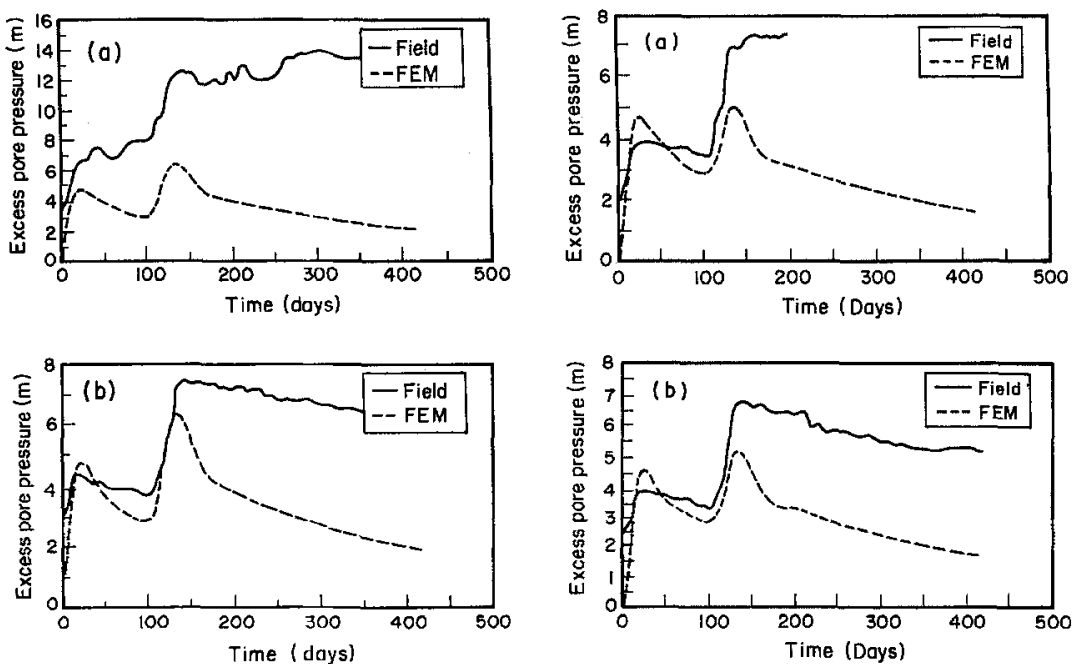

FIG. 7. Variation of Excess Pore Pressures at Embankment Centerline for Piezometers: (a) P5 at $9.1 \mathrm{~m}$ below Ground Level; and (b) P6 at $13.6 \mathrm{~m}$ below Ground Level

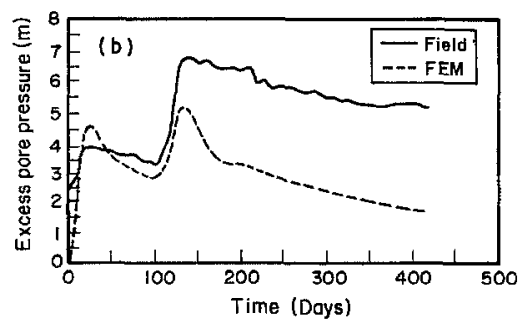

FIG. 8. Variation of Excess Pore Pressures, $23 \mathrm{~m}$ Away from Embankment Centerline for Piezometers: (a) P5 at 9.1 $\mathrm{m}$ below Ground Level; and (b) P6 at 13.6 below Gound Level 


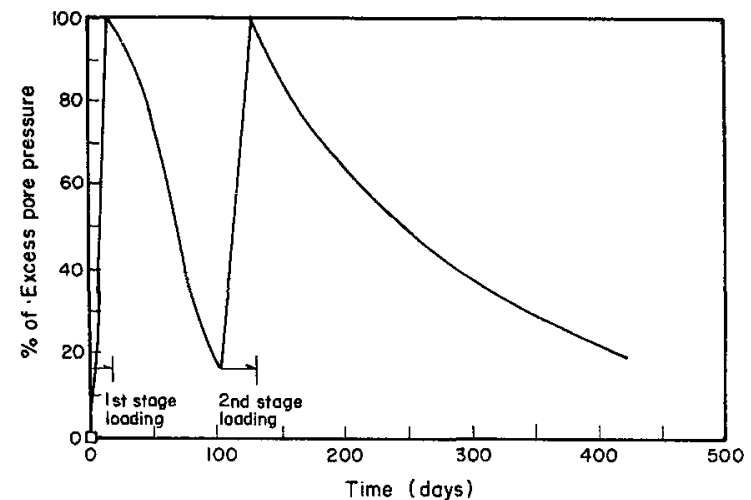

FIG. 9. Percentage of Undissipated Excess Pore Pressures at Drain-Soil Interfaces

proaches 2 , hence the predictions from the modified cam-clay model may deviate from accuracy. Figs. 7 and 8 illustrate the typical variation of the excess pore pressures with time along the centerline (P5 and P6) and $23 \mathrm{~m}$ to its left ( $\mathrm{P} 2$ and $\mathrm{P} 3)$, respectively.

Although the general trends between the finite element results and field data are in agreement especially during the initial stages, the marked discrepancy beyond 100 days is too large to be attributed solely to the plane strain assumption. These excess pore-pressures reflect the retarded efficiency of the vertical drains (partial clogging). Alternatively, the average undissipated excess pore pressures could be estimated by finite element back-analysis of the settlement data at the centerline of the embankment (Fig. 9). In this plot, 100\% represents zero dissipation when the drains are fully loaded. Accordingly, at the end of the first stage of construction (i.e., $2.5 \mathrm{~m}$ of fill after 105 days), the undissipated pore pressures decrease from $100 \%$ to $16 \%$. For the second stage of loading, the corresponding magnitude decreases from $100 \%$ to $18 \%$ after a period of 284 days, during which the height of the embankment has already attained the maximum of $4.7 \mathrm{~m}$. It can be deduced from Fig. 9 that perfect drain conditions are approached only after a period of 400 days.

\section{Surface Settlement-Analytical Predictions}

The centerline is also the line of symmetry of the embankment on which the lateral displacements are zero. Consequently, the analytical or numerical procedures can often be simplified at the line of symmetry. In this section, the predictions are based on the assumption of zero excess pore pressures at the drain boundaries. In other words, the drains are considered to be $100 \%$ efficient at all times. The consolidation settlement at ground surface was predicted from the equal strain solution for a single-drain model, which also incorporates the effect of smearing and well resistance (Barron 1948). Since the single-drain analysis assumes zero lateral deformation, it is justified only at the centerline of the embankment. In contrast, the settlments without drains were computed from the one-dimensional consolidation theory (Terzaghi 1943). The field measurements and the predictions from these simplified methods are illustrated in Fig. 10.

It is obvious that the installation of vertical band drains has a considerable 


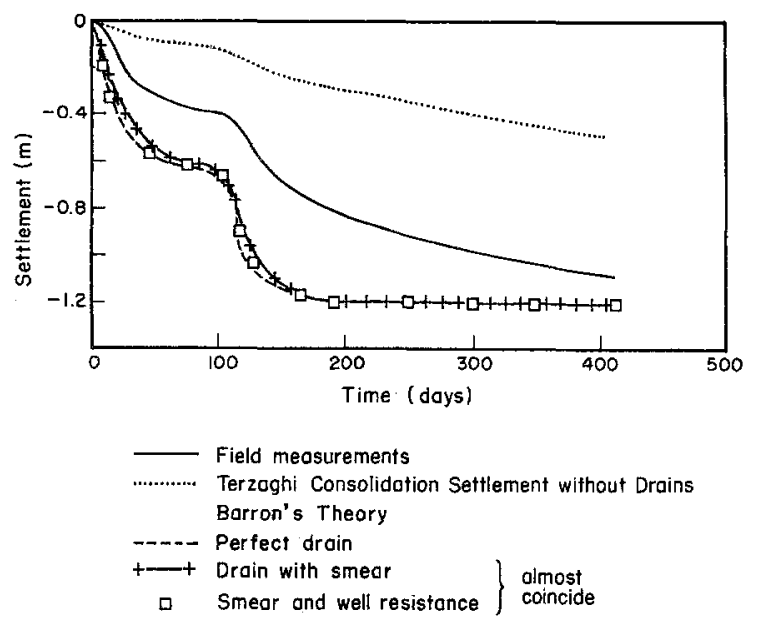

FIG. 10. Comparison of Consolidation Settlement at Ground Surface at Embankment Center

effect on the surface settlements. For instance, at the end of 400 days, the field measurements approach $90 \%$ consolidation, and its magnitude is a factor of 2.5 greater than the corresponding surface settlement without drains. However, in comparison with Barron's (1948) solution where complete consolidation is achieved in less than 250 days, the field measurements certainly indicate retarded pore-pressure dissipation at the drain boundaries, as illustrated earlier (Fig. 9). Fig. 10 further reveals that the influence of smearing is small (less than 10\%), and is negligible beyond 200 days. The inclusion of well resistance does not seem to have any further effect. This is not surprising, as noticeable well resistance is generally encountered for much longer drains (Ratnayake 1991).

\section{Settlements and Heave-Finite Element Analysis}

The single-drain analysis and one-dimensional consolidation analysis are not sufficient to investigate the overall behavior of the soft clay foundation. An extensive consolidation analysis of the clay layers below the entire embankment (including all vertical band drains) is required for the prediction of settlements and lateral displacements away from the centerline. A few very important assumptions have been made in this finite element analysis. To execute CRISP within its limitations: (1) Plane strain conditions were assumed; and (2) the stiffness of the drain was considered to be the same as that of the adjacent soil element. As the effect of smearing and well resistance was not substantial, the detailed finite element analysis was performed for the two extreme cases: with perfect drains and without drains. For perfect drains, the excess pore pressures at the drain boundaries were assumed to be zero.

The consolidation settlements determined by the finite element analysis are illustrated in Fig. 11, together with the predictions for an identical embankment without drains. The field data and numerical predictions are plotted for the ground surface, and at depths of $5.5 \mathrm{~m}$ and $12 \mathrm{~m}$, respectively, along the centerline. As a supplementary exercise, a simplified finite element analysis was also conducted for an axisymmetric single drain, including the 

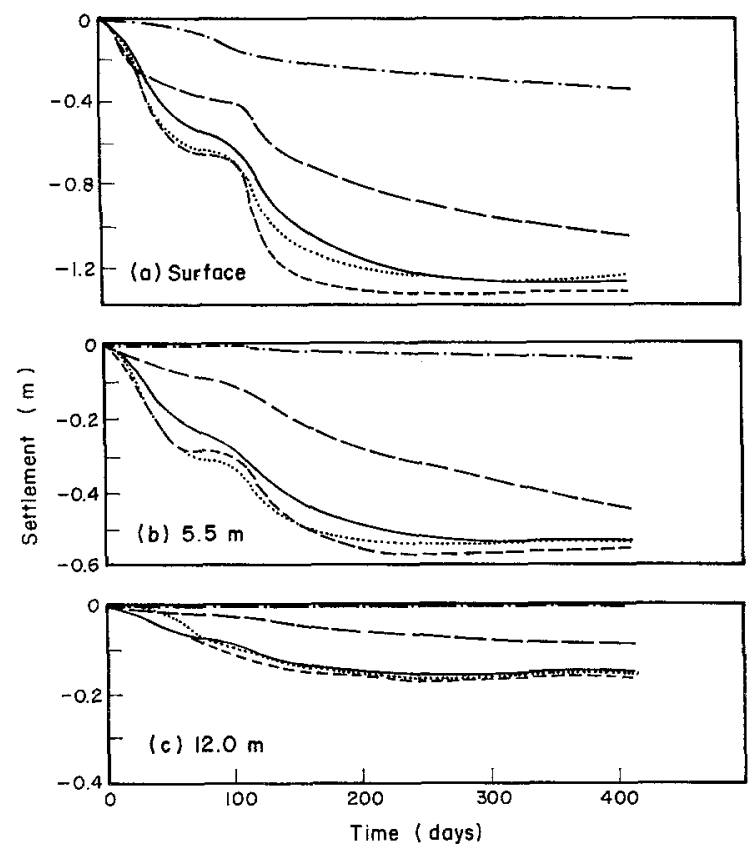

- Field meosurements

Finite Element Analysis with Single Drain Model

............. Perfect droin

Drain with smeor

Finite Element Analysis

----- Perfect drains

-.- Without drains

FIG. 11. Consolidation Settlement along Centerline of Embankment at Various Depths

smear effect. In this analysis, the discretized mesh was confined within the influence zone of a single drain, without allowing lateral deformations at the boundaries. The corresponding predictions are also plotted in Fig. 11. The single-drain analysis confirms that the effect of smearing is insignificant particularly after 250 days, which is in accordance with Barron's (1948) solution.

The settlement rates obtained for the complete embankment with perfect drains are only slightly greater than the single-drain analysis. In other words, the assumption of plane strain at the center of embankment has not contributed to excessive settlements. However, both finite element solutions give significantly higher settlements than the field measurements. In particular, at a depth of $12 \mathrm{~m}$, the predicted settlements have reached the utlimate stage, whereas the measurements are still increasing. At the end of the first loading stage ( 105 days), the field data indicate a surface settlement of $0.4 \mathrm{~m}$, which is only about $60 \%$ of the predicted value. However, at the end of 400 days, the predicted and measured surface settlements are $1.28 \mathrm{~m}$ and $1.13 \mathrm{~m}$, respectively, giving a more acceptable drain efficiency of $87 \%$ in the longer term. The high initial settlements shown by perfect drains is due not only to the assumption of zero excess pore pressures but 
also to the plane strain condition, which indirectly considers drains in the third dimension. The assumption of the associated flow rule (normality condition) in the cam-clay model also contributes to increased displacements.

To conduct an accurate numerical analysis, the excess pore pressures remaining at the drain boundaries at a given time must be incorporated in the analysis rather than assuming perfect drains. For this purpose, additional subroutines were developed and used in conjunction with CRISP (Ratnayke 1991). In this modification, the nonzero excess pore pressures were computed via additional pore-pressure shape functions applied at the relevant nodes of the LSQ elements along the vertical dissipation boundaries. Figs. 12 and 13 illustrate the corrected settlements along the centerline and at a distance of $23 \mathrm{~m}$ to its left. As expected, the modified results provide an excellent match with the field response from the ground surface up to a depth of $12 \mathrm{~m}$.

Although the analysis of perfect drains generally indicates higher initial settlements, the ultimate settlements are reasonably close to the field values. In contrast, $23 \mathrm{~m}$ away from the centerline, the field settlements after the second stage of embankment loading exceed the finite element predictions, and beyond 400 days, the field settlements are even greater than the predictions based on perfect drains. One probable reason for this may be the

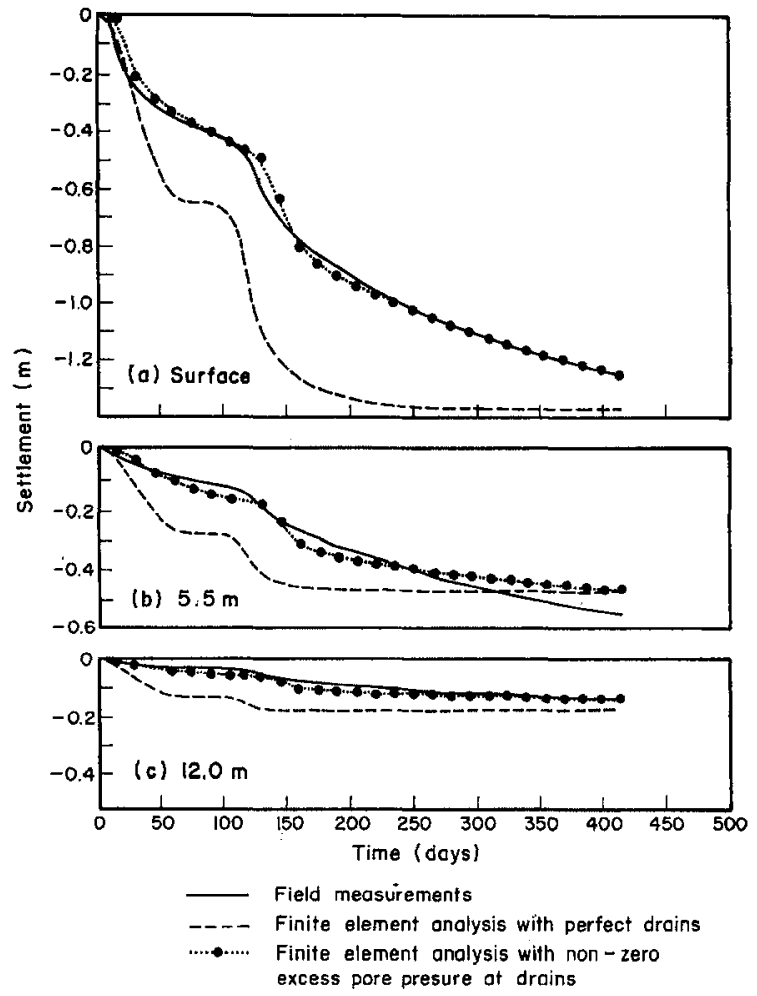

FIG. 12. Comparison of Finite Element Analysis with Field Measurements along Embankment Centerline 


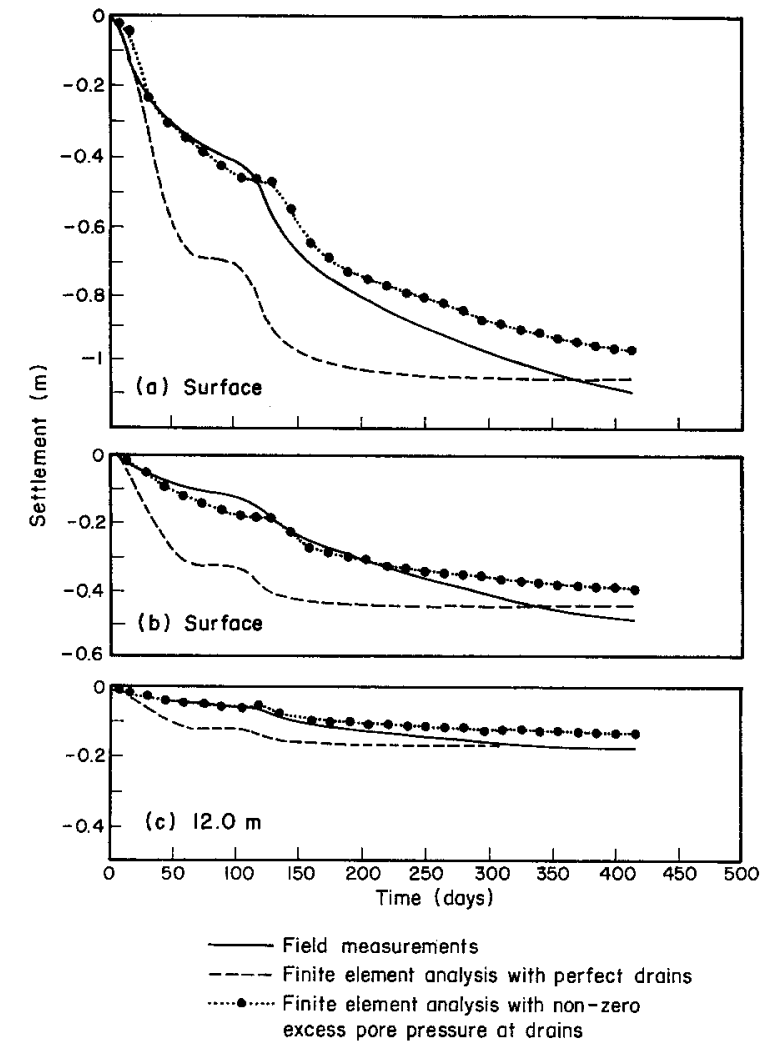

FIG. 13. Comparison of Finite Element Analysis with Field Measurements $23 \mathbf{m}$ from Embankment Centerline

overestimation of heave by the finite element method beyond the toe of the embankment ( $43 \mathrm{~m}$ from the centerline), as shown in Fig. 14 for selected time periods. The maximum predicted heave of $0.1 \mathrm{~m}$ may be somewhat higher than the actual values, but as the heave measurements away from the toe are not available, definite conclusions cannot be made. In general, there is no doubt that the modified cam-clay theory is sufficient in predicting the surface settlement profile, if the undissipated excess pore pressures at the drain boundaries are accounted for, as verified in Fig. 14. As the actual field conditions are partially drained, realistic prediction of surface settlements should be anticipated from a coupled consolidation analysis rather than from a purely undrained or purely drained analysis.

\section{Lateral Displacements}

The variation of in situ lateral displacements with time at the location of the inclinometer (SD1) is illustrated in Fig. 15. These lateral displacements can be considered as incremental or creep, as the initial lateral movement due to surcharge loading has been subtracted from the total lateral displacements observed at any given time. As expected, the maximum displacements are measured within the upper soft clay layer, whereas within the deeper (stiffer) deposits, the lateral movements are severely curtailed. 

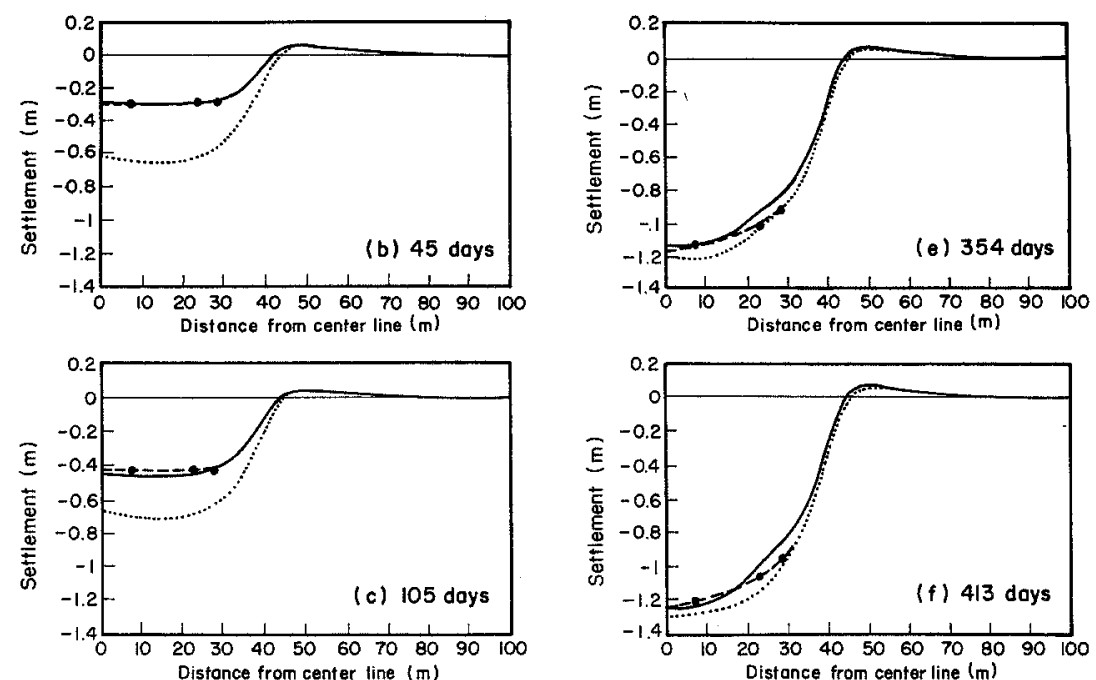

-- Field measurements

Finite element analysis with perfect drains

Finite element analysis with non-zero

excess pore pressure dissipation at drains

FIG. 14. Surface Settlement Profiles at Selected Time Periods

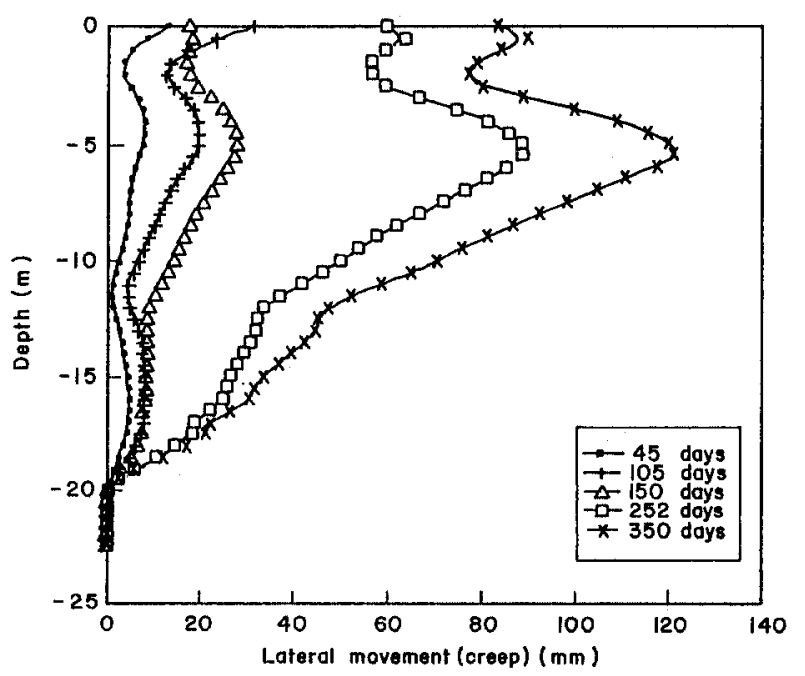

FIG. 15. Development of Lateral Movements at Various Time Periods

However, it is of interest to note the effect of the overconsolidated crust on the lateral displacements within the uppermost $2 \mathrm{~m}$ of the foundation. It is obvious from Fig. 15 that the incremental lateral movements at a depth of $5 \mathrm{~m}$ are considerably larger than the measurements at any other depth, which is indicative of the probable development of a slip surface at this 

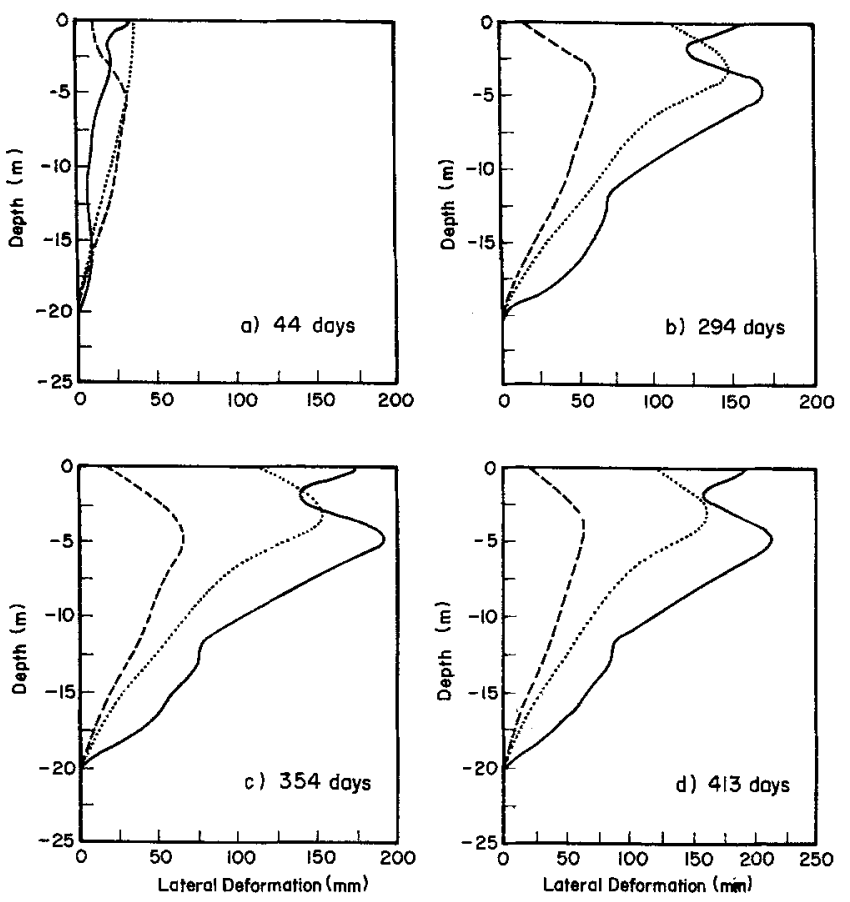

- Field Measurements

--- Finite Element Analysis with perfect Drains

Finite Element Analysis with non - zero

excess pore pressure of drains

FIG. 16. Lateral Deformation Profiles at Inclinometer Location (23 $\mathrm{m}$ from Centerline)

depth if the embankment has been constructed to failure. Total lateral displacements as measured in the field are plotted with the finite element predictions in Fig. 16, for time periods of 44, 294, 354, and 413 days, respectively. As expected, the predictions based on perfect drains are considerably lower than the field measurements, while the recognition of nonzero excess pore pressures at the drain boundaries provides a more realistic comparison.

Previous studies on embankments have shown that the accurate prediction of lateral displacements is a formidable task, in comparison with vertical displacements (Poulos 1972; Indraratna et al. 1992). The errors made in the prediction of lateral movements can be numerous. For instance, the stiff surficial crust restricts the lateral deformation just beneath the embankment to some extent. This process could not be accurately modelled in the analysis, due to the absence of geotechnical data for the overconsolidated crust. In this finite element analysis (CRISP), the modified cam-clay parameters have been obtained from triaxial $C K_{0} U$ stress-strain behavior. The magnitudes of soil parameters determined in the laboratory are influenced by the initial stress history and the subsequent stress paths followed under given loading-unloading conditions. Although the cam-clay theory proposes the soil parameters $(\lambda, \kappa$, and $M)$ to be unique for a specific yield surface, the 
laboratory determination of their magnitudes can be influenced by the nature of stress path testing.

\section{CONCLUSIONS}

The performance of an embankment constructed on a soft foundation stabilized with vertical band drains was analyzed in this study. The effectiveness of the vertical band drains could be evaluated by considering the excess pore-water pressures, vertical and lateral displacements, and the surface settlement profile in relation to the consolidation behavior of the soft clay. For efficient vertical drains, this case study reveals that the effect of smear and well resistance is generally negligible. In the short term, the rate of dissipation of the excess pore pressures at the drain-soil boundaries controls the drain efficiency, and hence the consequent settlements. In the long term (more than 400 days), the assumption of perfect drain seems to be realistic.

In the short term, the assumption of zero excess pore pressures at the drain boundaries overestimates vertical settlements but underestimates the lateral yield. For perfect drains, although the prediction of initial or shortterm vertical settlements is conservative, significant underprediction of the lateral movements is of greater concern. This is because the propagation of failure surface is mainly a function of the incremental lateral displacements within the upper soft clay (Donald and Giam 1989; Indraratna et al. 1992). Therefore, to evaluate the stability of a rapidly built embankment on soft clay, the excess-pore-pressure conditions at the drain boundaries must be correctly incorporated into the finite element analysis at any given time. This study has shown that unless the undissipated excess pore pressures along the drain boundaries are correctly accounted for, the vertical settlements and lateral displacements cannot be predicted to an acceptable degree of accuracy. In this respect, the addition or modification of the pore-pressure shape functions of the elements along the soil-drain boundaries is desirable.

The accurate prediction of lateral displacements require careful assessment of soil parameters corresponding to the actual stress path response in the field, during embankment loading. The installation of vertical band drains curtails the lateral displacements substantially, thereby minimizing the risk of shear failure (slip surface). The existence of a rigid crust just beneath the embankment can also resist lateral displacements, facilitating the construction of higher embankments.

The use of a plane strain finite element analysis (CRISP) cannot be regarded superior to a more powerful three-dimensional analysis of flow into vertical drains. Nevertheless, considering the relative simplicity of the modified cam-clay theories and the user-friendly CRISP, the current analysis is justified in terms of both computational effort and the acceptable quality of predictions.

\section{ACKNOWLEDGMENTS}

The writers gratefully appreciate the support of the Malaysian Highway Authority. The writers wish to extend their thanks to Robert Hudson and Ted Brand (Geotechnical Control Office, Hong Kong) for their advice and technical assistance. The assistance of $\mathrm{A}$. Britto and S. Balachandran (Cambridge University, Cambridge, England) is appreciated. Useful comments made by R. N. Chowdhury (University of Wollongong, Wollongong, New South Wales, Australia) are also acknowledged. 


\section{APPENDIX, REFERENCES}

Balachandran, S. (1990). "Simulation of a test embankment failure (Muar flood plain, Malaysia) using finite element techniques coupled with critical state soil mechanics," MS thesis, Asian Institute of Technology, Bangkok, Thailand.

Barron, R. A. (1948). "Consolidation of fine-grained soils by drain wells." Trans., ASCE, 113, 714-742.

Bjerrum, L. (1973). "Problems of soil mechanics and construction on soft clays." Proc., 8th Int. Conf. Soil Mech. and Found. Engrg., International Society of Soil Mechanics and Foundation Engineering, 3, 111-159.

Britto, A. M., and Gunn, M. J. (1987). Critical state soil mechanics via finite elements. Ellis Horwood, Chichester, U.K.

Donald, I. B., and Giam, P. S. K. (1989). "Improved comprehensive limit equilibrium stability analysis." Civil Engineering Research Report No. 1/1989, Monash Univ., Melbourne, Australia.

Hansbo, S. (1981). "Consolidation of fine-grained soils by prefabricated drains." Proc., 10th Int. Conf. Soil Mech. and Found. Engrg., International Society of Soil Mechanics and Foundation Engineering, 3, 677-682.

Indraratna, B., Balasubramaniam, A. S., and Balachandran, S. (1982). "Performance of test embankment constructed to failure on soft marine clay." J. Geotech. Engrg., ASCE, 118(1), 12-33.

Indraratna, B., Dilema, E. L. G., and Nutalaya, P. (1990). "Stability of lateritic residual soil for core compaction and design of appropriate granular filters." Dam Engrg., 1(3), 201-220.

Poulos, H. G. (1972). "Observed and predicted behavior of two embankments on clay." Geotech. Engrg. J. Southeast Asian Geotech. Soc., Hong Kong, 3(1), 1-20.

Proceedings of International Symposium on Trial Embankments on Malaysian Marine Clays. (1989). Vols. 1 and 2, Malaysian Highway Authority, Kuala Lumpur, Malaysia.

Ratnayake, A. M. P. (1991). "Performance of test embankments with and without vertical drains at Muar Flats site, Malaysia," MS thesis, Asian Institute of Technology, Bangkok, Thailand.

Roscoe, K. H., and Burland, J. B. (1968). "On the generalized stress strain behavior of wet clay." Engineering plasticity. Cambridge Univ. Press; Cambridge, U.K., $535-609$.

Terzaghi, K. (1943). Theoretical soil mechanics. John Wiley and Sons, New York, N.Y. 